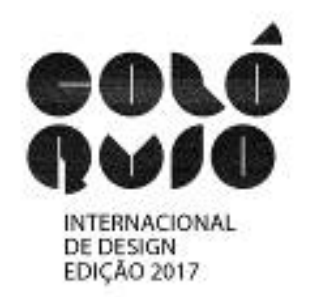

\title{
Aplicação semiótica a projetos de produto: estudo de caso do polo moveleiro ubaense
}

\author{
Anna Clara A. Do N. Leite; \\ Taís Alves Coutinho;
}

resumo:

O projeto visa entender como se dá a relação entre a semiótica e o design dentro das empresas do maior polo moveleiro de Minas Gerais, Ubá, analisando-o com a realização de pesquisas de campo, entrevistas com designers das referidas empresas, e análises de materiais de divulgação, sempre confrontando a teoria com o que acontece na prática, a fim de estimular discussões acerca dos possíveis benefícios de sua aplicação para o polo, seja por questões simbólicas ou pelo valor que é agregado, e a importância do estudo da semiótica para o design, que, segundo os dados obtidos, apesar de alguns incentivos para a busca da diferenciação semântica dos produtos da região, ainda há a falta de interesse em investimentos voltados a utilizar o design como um diferencial competitivo, principalmente em um momento de crise econômica, pois ainda não se reconhece todo o potencial estratégico do design para polo moveleiro ubaense.

palavras-chave:

Design; Semiótica; Ubá; móveis. 


\section{Introdução}

Ubá é uma cidade mineira localizada a $290 \mathrm{~km}$ da capital cuja as indústrias moveleiras concentram mais de $50 \%$ dos empregos diretos na região, sendo uma fonte de renda importante para muitas famílias. O polo moveleiro é composto também por mais sete cidades: Guidoval, Piraúba, Rio Pomba, São Geraldo, Rodeiro, Tocantins, e Visconde do Rio Branco. Ao todo são 338 estabelecimentos industriais de móveis no pólo, sendo 218 instaladas em Ubá.

As indústrias moveleiras ubaenses começaram a surgir há mais de oito décadas. Os primeiros estabelecimentos eram pequenas mercearias, porém, o marco para o desenvolvimento da movelaria industrial está nos primeiros anos da década de 1960, quando se iniciam as atividades de dois grupos que, até hoje, são bastante importantes na região: a fábrica de móveis de aço Itatiaia e o grupo Parma, criado pelo pioneiro José Francisco Parma. O setor de indústria substituiu as economias do fumo, do café e do milho que até então reinavam, porém, na época, se encontravam em declínio. (Intersind, 2015).

Em 1986, com a união de alguns empresários que almejavam trazer melhorias ao setor foi criado a "Associação de Fabricantes de Móveis", que, futuramente, se chamaria INTERSIND Sindicato Intermunicipal das Indústrias do Mobiliário de Ubá. Hoje, apesar de não ser conhecido por muitos, Ubá é considerado o maior polo moveleiro de Minas Gerais e o $5^{\circ}$ maior do Brasil, e, dentro deste setor, o design é importante instrumento de inovação para as empresas.

A medida com que o design evoluiu, houve uma ampliação do papel no mercado, adquirindo uma crescente força de seu caráter estratégico. O profissional possui, além do papel na manutenção da produção e da circulação de produtos e serviços, uma relevante contribuição para o aumento da qualidade de vida social e individual do consumidor, demonstrando a importância de estar atento às possíveis relações comunicativas entre o produto e o usuário (Niemeyer, 2003, p.15-16).

Levando em consideração a relevância de seu estudo e aplicação nos projetos de design, a pesquisa visa investigar como a semiótica é aplicada no polo moveleiro de ubá e promover a discussão a importância de seu estudo, as vantagens que ela pode trazer para as empresas da região e a sua capacidade de oferecer um diferencial aos móveis ubaenses e dar a eles uma identidade.

\section{Importância da Semiótica para o Design}

No âmbito do design, a semiótica está diretamente ligada a função simbólica dos objetos descrita por Löbach (2001, p.64): "Um objeto tem função simbólica quando a espiritualidade do homem é estimulada pela percepção deste objeto, ao estabelecer ligações com suas experiências e sensações anteriores. " O produto, além das funções de estética e de uso, possui então, função significativa e difunde valores e características culturais no âmbito que atinge (Niemeyer, 2003, p.14). Com isso, podemos concluir que o produto faz parte de um processo de comunicação, e que o design pode ser considerado uma linguagem, sendo então possível ser estudado pela semiótica pois ela é a ciência que utiliza como objeto de estudo todas as linguagens possíveis (Baida; Nojima, 2014 apud SANTAELLA, 2001, p.13).

A Semiótica também é descrita como o estudo dos signos. O signo segundo Peirce (1955): "é aquilo que, sob certo aspecto ou modo representa algo para alguém". Ele gera associações nas mentes dos indivíduos causando reações, que podem ser tanto positivas, neutras ou negativas, e toda a comunicação é feita por meio da associação de signos. Quando sentimos um cheiro que nos remete a algum tipo de comida ou experiência, este odor é um signo, pois para o indivíduo ele representa alguma coisa. (Torres, 2006, p. 106). Para um produto, os signos podem ser representados de diversas formas, para Ellinger (1966 apud Bürdek, 2006, p.285):

"Pertencem à linguagem do produto diversas formas de expressão como p. ex. dimensão, forma, estrutura física da superfície, movimento, características do material, forma de preencher a função, cores e configuração gráfica da superfície, ruídos e tons, sabor, cheiro, temperatura, embalagem, resistência a influências externas."

Isto pode ser usado de maneira estratégica em um projeto de Design, com o objetivo de obter uma certa reação do usuário, como por exemplo, tornar certo produto um símbolo de qualidade, e até mesmo agregar valor de estima a uma marca associando-a a algo positivo. Para demonstrar a 
importância da linguagem do produto e como ela influencia a forma como pensamos Bürdek cita Umberto Eco (1972) que utiliza como exemplo o trono, que, apesar de ser uma cadeira, sua função não é apenas sentar. O trono deve transmitir majestade, ser uma representação de poder. Assim como em uma cadeira de escritório se deve transmitir a posição hierárquica de seu usuário, além de atender preceitos ergonômicos.

Importante levar em consideração também que a forma como um signo é interpretado depende do contexto cultural no qual se dá o processo de comunicação, logo, para se projetar de maneira adequada deve-se ter uma compreensão e domínio do grupo cultural em que o produto irá circular, entendendo aspectos quanto tradições, costumes, valores, religiões, características políticas e econômicas dos usuários envolvidos na etapa inicial do projeto para evitar a perda de tempo com ajustes no futuro ou até mesmo o seu fracasso. (Bürdek, 2006)

A semiótica também está relacionada com a identidade de um produto ou marca, Niemeyer (2003) cita que a identidade pode ser vista segundo três tipos de informação:

- A informação de existência, onde o produto estabelece sua própria condição fenomênica

- A informação sobre origem, a qual o produto informa o designer, a região que foi produzida, o fabricante, a cultura;

- A informação sobre a qualidade, onde o produto informa sobre sua função, modo de uso, e manutenção.

A busca pela identidade é um fator importante para uma empresa, pois está relacionada aos atributos que tornam uma marca especial e diferenciada, seja por seus valores ou características particulares, agregando valor ao seu nome e aos seus produtos.

Como já foi citado, a identidade também pode ser associada ao local produzido, trazendo valor de estima para os produtos de determinada região, ao passo que, ao apresentar elementos considerados particulares de determinada localidade, seu público-alvo irá reconhecê-los e responder emocionalmente a mensagem transmitida, podendo associar os produtos regionais a algo exclusivo, de qualidade, ou com algum elemento diferenciado que os agrade.

\subsection{Aplicação da semiótica no projeto de design}

Segundo Lucy Niemeyer (2003), para que algo seja produzido, o empresário e o designer constituem um elemento do processo de comunicação que denominamos de "gerador", este gerador ao projetar utiliza um conhecimento que possa ter, seja tecnológico ou cultural, que possibilita que o produto tome forma e carregue os elementos que viabilizem sua comunicação, que não necessariamente se dá apenas com o usuário final que utilizará o produto, pois o projeto de design pode envolver desde quem contratou o serviço, os fornecedores, quem comercializará o produto, até chegar o seu público alvo, por isso utiliza-se o termo interpretador, que é uma denominação mais abrangente. Niemeyer (2003) adverte que:

“(...) o designer deve conhecer as intenções, metas, exigências e limitações do seu cliente e se preocupar com características geográficas, temporais e sócio econômicas não só do usuário visado, mas até mesmo a comunidade geral, até mesmo aqueles que dificilmente se aproximarão de fato do produto"

Niemeyer (2003) propõe então que para a aplicação da semiótica no projeto de design é necessário, primeiramente, identificar os valores centrais, ou seja, investigar a personalidade dos que estão responsáveis pela empresa e analisar junto a eles o que se espera, os desafios, os objetivos que pretendem atingir.

Deve-se também construir um personagem, ou seja, é necessário que seja bem claro as características fundamentais do público que o projeto se destina, para isso, pode-se utilizar uma ferramenta, muito utilizada no marketing, chamada persona, onde se constrói um personagem que caracterize o interpretador, analisando assim o repertório do público a ser tratado, ou seja, seus valores culturais, sociais, entre outros, que é primordial para a maneira como se dará o processo comunicacional entre o produto e o consumidor. 
Em segundo momento, deve-se encontrar uma voz visual, processo que deve ser feito em equipe com todos os interessados no projeto cujo objetivo é o de entender os valores essenciais do projeto. É essencial nesta etapa que se liste palavras que possam expressar valores para determinado público, e logo após, fazer uma síntese, escolhendo três ou quatro palavras, após isso, Niemeyer (2003) propõe a utilização de imagens aleatórias que, a partir de uma análise, deve-se separar as imagens que evoquem os sentimentos buscados e observar os elementos configuracionais que provocam tais sensações para que se possa então gerar alternativas associando signos ao produto a ser projetado.

Por último, como conclui Torres (2006), é necessário averiguar como está se dando a comunicação entre o usuário e o produto, como ele o interpreta, e que reação a simbologia está provocando no consumidor, pois ela pode ser tão positiva como negativa, ou, em alguns casos, a comunicação pode não ocorrer, pois, reiterando, a semiótica está relacionada ao repertório do usuário, ou seja, questões ligadas à cultura, valores, entre outros aspectos.

\section{Metodologia}

Em primeiro momento na pesquisa foi promovido um levantamento preliminar de dados sobre o tema com uma pesquisa bibliográfica com a finalidade de promover a fundamentação teórica. Nesta etapa, além do entendimento sobre conceitos semióticos de autores como Peirce, Lúcia Santaella, Umberto eco e Lucy Niemeyer, que serviram de base para a compreensão da relação da semiótica com o design e os benefícios que a sua aplicação traz na elaboração de projetos de desenho industrial, foi essencial a coleta de dados sobre a região e suas indústrias que atuam no setor moveleiro, cedidos a maior parte pelo Intersind, para entendermos o contexto atual em que trabalham as empresas ubaenses, sua importância para a economia da cidade e quais são as características principais do polo em relação ao resto do país e do mundo.

A segunda etapa visava investigar como a semiótica era tratada pelos setores criativos do polo moveleiro. $\mathrm{O}$ instrumento para a coleta destes dados foi uma entrevista estruturada, que é descrita por Lakatos e Marconi (2003), onde "o entrevistador segue um roteiro previamente estabelecido; as perguntas feitas ao indivíduo são predeterminadas". Este tipo de entrevista propõe que todas as perguntas sejam as mesmas para todos os entrevistados, possibilitando "que todas elas sejam comparadas com o mesmo conjunto de perguntas, e que as diferenças devem refletir diferenças entre os respondentes e não diferenças nas perguntas". (LODI, 1974:16, apud LAKARTOS; MARCONI, 2003, p. 197)

A entrevista foi realizada com cinco profissionais da área do Design que trabalham juntamente com as empresas deste segmento na região com o propósito de examinarmos como funciona seu processo de criação e se era de preocupação dos setores criativos a comunicação entre

A fim de analisar a produção moveleira de maneira abrangente, foram selecionados representantes que trabalham em empresas moveleiras de diferentes portes, visando observar também se há diferença em como se trata o processo de criação entre as mesmas.

\section{Resultados e discussão}

Como se observa no quadro 1 , os resultados demonstram que a maioria das empresas entrevistadas possuem um setor de criação, mesmo que terceirizado, mas que a maioria dos profissionais possuem formação técnica. No quadro 2 nota-se que a maioria dos projetos desenvolvidos são baseados em análises do que está em voga no mercado, principalmente do exterior. Como já foi constatado por Maria Luiza A. C. de Castro e Juliana Cardoso (2010), por um lado, apesar de haver uma crescente contratação de designers pelas empresas, em contrapartida, o polo moveleiro não parece buscar um diferencial no design, visto que a maioria dos produtos são desenvolvidos baseados em tendências dominantes, o que culmina em produtos sem nenhuma identidade. Esta prática é muito comum na maioria dos polos moveleiros no Brasil e não parece se limitar a empresas pequenas. No polo Ubaense, esta maneira de projetar se dá muitas vezes pela falta de uma formação acadêmica desses profissionais, visto que a maioria possui apenas formação técnica, que possui um enfoque maior nos aspectos funcionais e estéticos do objeto e quase não aborda os aspectos simbólicos em projetos de produto. 
Quadro 1 - Possui setor de criação? Como é composto?

\begin{tabular}{c|c} 
Empresa & Resposta \\
\hline A & Sim. É composto por quatro técnicos em design, e um gerente de produto. \\
\hline B & Apesar de ter designers formados empregados, o trabalho de criação (Formação do \\
conceito do produto), em geral é terceirizado.
\end{tabular}

Quadro 2 - Como surgem as ideias das coleções ou de determinados produtos?

\begin{tabular}{|c|c|}
\hline Empresa & Resposta \\
\hline $\mathbf{A}$ & $\begin{array}{c}\text { A inspiração vem geralmente de pesquisas de produtos internacionais e de decoração em } \\
\text { geral. }\end{array}$ \\
\hline B & $\begin{array}{l}\text { Com base em pesquisas de mercado, os designers elaboram uma geração de alternativas } \\
\text { para criação de produtos que atendam a demanda da pesquisa. }\end{array}$ \\
\hline $\mathbf{C}$ & O desenvolvimento acontece através das tendências e o que mercado busca. \\
\hline $\mathbf{D}$ & $\begin{array}{c}\text { A partir de pesquisas de mercado se identifica uma demanda para o desenvolvimento do } \\
\text { produto }\end{array}$ \\
\hline $\mathbf{E}$ & $\begin{array}{l}\text { O setor comercial passa uma demanda e o setor de design faz o necessário para a criação } \\
\text { do produto baseada nessa demanda que é observada através de pesquisa de mercado e } \\
\text { tendências }\end{array}$ \\
\hline
\end{tabular}

Fonte: Elaborado pelo autor, com base na pesquisa realizada

As respostas presentes no quadro 3 confirmam a realização desta prática nas empresas, visto que, ao serem questionados sobre se há uma pesquisa direta com os consumidores para entender o que se espera de seus produtos, a maioria dos entrevistados demonstra que na etapa de criação o consumidor final é pouco citado, sendo as tendências do mercado o fator mais importante para a criação do produto, e muita das vezes, quando há uma pesquisa voltada ao usuário, ela é realizada por uma empresa terceirizada. Nota-se que algumas empresas estão se preocupando em fazer pesquisas de satisfação do consumidor para a melhoria do serviço prestado, porém, essa investigação pouco é associada a aplicação da semiótica nos projetos dos móveis. O resultado são produtos muito parecidos, que apenas competem entre si pelo preço, pois as marcas pouco se diferenciam ou possuem uma identidade forte. No âmbito nacional, os produtos se misturam com outros semelhantes por não terem nenhum diferencial que os destaquem e por isso, apesar do polo moveleiro de Ubá ser o $5^{\circ}$ maior do país, ele é pouco reconhecido.

Como visto no quadro 4, ao serem indagados se o conceito do produto era um fator considerado em algumas das etapas de execução dos projetos as respostas foram diversas, ao passo que algumas respostas foram negativas, observa-se um reconhecimento da importância do significado do produto por outras empresas, isto se deve ao fato de que algumas empresas estão exportando seus produtos pra diversas regiões do país e do mundo, identificando a necessidade de se adequar aos diferentes mercados, pois a maneira como o usuário entende o produto, como já mencionado, está ligado ao seu repertório, o que demonstra uma necessidade de se projetar utilizando o público final como foco. 
Quadro 3 - Há uma pesquisa para identificar o que o consumidor busca no móvel ubaense?

\begin{tabular}{c|c} 
Empresa & Resposta \\
\hline $\mathbf{A}$ & Não é feita pesquisa direta com cliente final. \\
\hline $\mathbf{B}$ & $\begin{array}{r}\text { Sim, porém é terceirizada. Durante este processo, busca-se desenvolver o conceito } \\
\text { através do público, inclusive o nome. }\end{array}$ \\
\hline $\mathbf{C}$ & O desenvolvimento acontece através das tendências e o que mercado busca. \\
\hline $\mathbf{D}$ & $\begin{array}{c}\text { A partir de pesquisas de mercado se identifica uma demanda para o desenvolvimento } \\
\text { do produto. Também é muito utilizado ferramentas de pesquisa de satisfação dos } \\
\text { usuários. }\end{array}$ \\
\hline $\mathbf{E}$ & $\begin{array}{c}\text { O setor comercial passa uma demanda e o setor de design faz o necessário para a } \\
\text { criação do produto baseada nessa demanda que é observada através de pesquisa de } \\
\text { mercado e tendências }\end{array}$ \\
\hline
\end{tabular}

Fonte: Elaborado pelo autor, com base na pesquisa realizada

Quadro 4 - Preocupam-se com o conceito/significado do produto em alguma das fases de elaboração e execução do projeto de produto?

\begin{tabular}{c|c} 
Empresa & Resposta \\
\hline $\mathbf{A}$ & Não. \\
\hline $\mathbf{B}$ & $\begin{array}{c}\text { Sim, desde o início. Levam-se em consideração todas as regiões onde o móvel será } \\
\text { comercializado. Em alguns lugares o nome, cor ou forma do produto pode trazer } \\
\text { significado diferente que reflete na aceitação. }\end{array}$ \\
\hline $\mathbf{C}$ & $\begin{array}{c}\text { Não, o importante no desenvolvimento do produto é fazer com que não fique caro a } \\
\text { produção do mesmo. Também é considerado a estética e funcionalidade do produto. }\end{array}$ \\
\hline $\mathbf{D}$ & $\begin{array}{c}\text { Muito pouco, a maior preocupação é com o processo produtivo, normas e a segurança } \\
\text { da criança no uso do produto. }\end{array}$ \\
\hline $\mathbf{E}$ & $\begin{array}{c}\text { Antes criarmos a coleção para o próximo ano é definido um conceito que irá nortear } \\
\text { tanto a criação de produto como a criação gráfica, que também é feita dentro da } \\
\text { empresa. }\end{array}$
\end{tabular}

Fonte: Elaborado pelo autor, com base na pesquisa realizada

Importante citar que o INTERSIND e o SEBRAE promoveram algumas ações como a Coleção Móveis de Minas que utilizou de signos que remetiam às características de Ubá, a Zona da Mata e Minas Gerais. Esta coleção de móveis promovia resgatar símbolos da cultura mineira e decodificar os aspectos locais como um diferencial para a concepção destes produtos, visando assim, atribuir um maior valor agregado as peças e aumentar o faturamento das empresas de Ubá (SEBRAE, 2004), porém, estas iniciativas não tiveram uma sequência, mesmo tendo sido relevantes. Conforme Castro e Cardoso (2010) evidenciam, isso se dá pois há uma resistência por parte das empresas:

"As tentativas institucionais de um direcionamento neste sentido não levaram ao sucesso comercial, pelo fato de os produtos terem custos mais elevados ou não se adequarem ao segmento de mercado alvo do polo. Portanto, o estímulo promovido pela existência de políticas públicas envolvendo atividades inovadoras de design - tais como os financiamentos e subvenções da inovação, a disponibilização de estrutura de pesquisa das universidades, bem como dos projetos apresentados por iniciativa de seus pesquisadores - têm sido subaproveitados." 
Segundo as pessoas entrevistadas, observa-se também que mesmo tendo uma melhora nos últimos anos, ainda há uma desvalorização do trabalho do designer numa empresa, que é muitas vezes considerado um gasto desnecessário, e a tendência é que a situação piore pela região se encontrar em um momento de crise.

Nota-se que ao contrário do que acontece nos setores de criação, a semiótica é muito utilizada no marketing, que possui a consciência do quanto a sua aplicação pode influenciar as massas. Como exemplo, podemos citar a campanha da Parma (figura 1) que utiliza a marca como sinônimo de qualidade e prestígio.

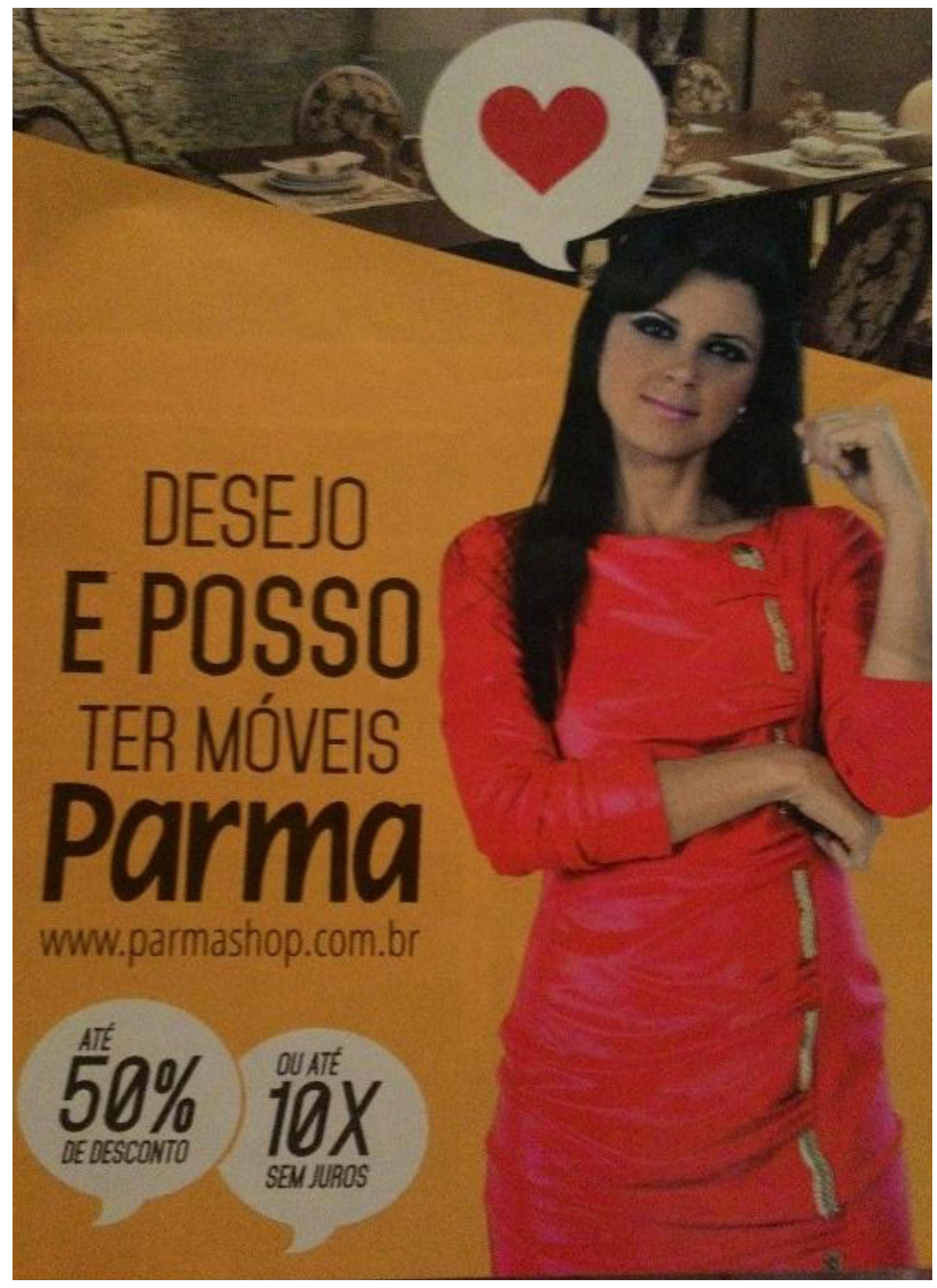

Figura 1 - Propaganda da Parma

Fonte: Material Publicitário da Parma, 2016

Niemeyer (2003) expõe possíveis causas para que o emprego da semiótica ainda não seja habitual no projeto de design quanto é na área de marketing, por exemplo, como a falta de aprofundamento teórico nos cursos de design, a falta ou a deficiência fundamentação teórica dos profissionais e como os próprios designers entendem seu trabalho, que muitas vezes é vista como uma profissão que busca apenas o embelezamento do produto. $\mathrm{O}$ investimento da capacitação destes 
profissionais é muito importante. Há uma necessidade de se conscientizar das vantagens econômicas de ter uma abordagem centrada nos usuários ao se projetar, e a semiótica trabalha exatamente com as possíveis reações do usuário, influenciando o interesse do público no produto trabalhado.

Para Castro e Cardoso (2010):

"[...] a busca de um design diferenciado, mesmo que não seja ainda parte do cotidiano do polo, é uma necessidade emergente, tornando-se, portanto, essencial para um processo de construção de valor simbólico e de competências. Neste sentido pode haver estímulos de instituições, sob pena de levar os resultados exitosos a um vocabulário inovador e uma diferenciação semântica dos produtos. "

\section{Conclusão}

Já foi constatado por diversos autores importantes para a semiótica e para o design como Lucy Niemeyer e Bürdek que a sua relação é essencial ser estudada e compreendida, e que a associação de signos ao produto e a marca pode ser uma poderosa ferramenta para o sucesso do produto. Logo, vê-se necessário uma contínua pesquisa voltada a busca de maneiras práticas de aplicação da semiótica e um estímulo aos estudos na área por parte dos profissionais de design.

No caso do polo moveleiro, a região passa por uma situação de crise devido a diminuição do número de vendas, em que, segundo o site de notícias G1 (2015), foram fechadas cerca de 12 fábricas de móveis nos últimos dois anos e o setor prevê a demissão de mais mil funcionários neste ano. Ao contrário do que se acredita, pode ser um bom momento de mudança na forma como se vê o design dentro das empresas, a partir do momento em que se reconhece o caráter estratégico do trabalho do designer.

Mesmo sendo um dos maiores polos moveleiros do Brasil, a cidade de Ubá possui pouca visibilidade fora da Zona da Mata, e isso se deve porque os produtos lá produzidos são, como evidencia a pesquisa, são baseados em elementos populares de produtos já existentes no mercado, fazendo com que os móveis ubaenses não possuam identidade e elementos que os destaquem no setor.

Para isso, deve-se ter um incentivo contínuo das instituições com o intuito de buscar uma diferenciação no mercado, utilizando a semiótica com o intuito de agregar valor simbólico aos produtos da região e trazendo uma vantagem competitiva que pode ser o posto-chave para o desenvolvimento do polo e a superação da crise.

\section{Semiotic application in product design: A case study of Ubá's furniture center}

Abstract: The project aims to understand how is the relationship between semiotics and design within the largest center of furniture industries of Minas Gerais, Ubá, analyzing it by conducting a field research, interviewing designers of these companies, and analyzing marketing materials, always confronting theory with what happens in practice in order to stimulate discussion about the possible benefits of its application to the city's products, whether by symbolic issues or the value proposition, and the importance of semiotic studies to design, which, according to information obtained, although there were some incentives for the pursuit of semantic differentiation of the products in the region, there is still a lack of interest in investments aimed to use design as a competitive advantage, especially in an economic crisis, because the design's strategic potential is still not recognized in the furniture center of ubá

Keywords: design; semiotic; Ubá; furniture. 


\section{Referências bibliográficas}

BÔAS, Bruno V. Polo de móveis em Minas Gerais demite trabalhadores e fecha fábricas. São Paulo: Folha de São Paulo, 2016. Disponível em <http://m.folha.uol.com.br/mercado/2016/02/1744346-polo-de-moveis-em-minas-gerais-demitetrabalhadores-e-fecha-fabricas.shtml> Acesso em 27 de fev 2016

BRAIDA, F.; NOJIMA, Vera L. Por que design é linguagem? Rio de Janeiro: Rio Book's, 2014. 90 p. BÜRDEK, Bernhard E. História, teoria e prática do design de produtos. São Paulo: Edgard Blücher, 2006.

CASTRO, Maria Luiza A. C. de; CARDOSO, Juliana. Inovação tecnológica e inovação narrativa: Caminhos para o design no polo moveleiro de Ubá. Campo Grande: Interações, 2010.

INTERSIND Informações sobre o polo moveleiro de Ubá. [mensagem pessoal]. Mensagem recebida por <anna.nascimento@uemguba.edu.br> data de recebimento, 28 de agosto de 2016. LÖBACH, B. (1976) Design Industrial: Bases para a configuração de produtos industriais. São Paulo: Blücher, 2001. 206 p.

MARCONI, Marina de Andrade; LAKARTOS, Eva Maria. Fundamentos de Metodologia Científica. 5. ed. São Paulo: Atlas, 2003.

NIEMEYER, L. Elementos de semiótica aplicados ao design. Rio De Janeiro: 2AB, 2003. 76 p. PEIRCE, Charles Sanders. Semiótica. 2a ed., São Paulo: Perspectiva, 1995

QUEIROZ, S.G.; CARDOSO, C.L.; GONTIJO, L.A. Design Emocional e Semiótica: caminhos para obter respostas emocionais dos usuários. 2013.

SEBRAE Coleção Ubá: Móveis de Minas. Belo Horizonte: Sebrae, 2004.

TORRES, M. A relevância do estudo da teoria da comunicação e da semiótica na formação e no aperfeiçoamento do profissional de design. In: Revista Design em Foco, v. III n.2, jul/dez 2006. Salvador: EDUNEB, 2006, p. 103-115. 